\title{
The Crossing as a New Approach for the Urban Transformation of Traditional Cities Towards the Sustainability
}

\author{
Ahmed A. Al-Jaberi ${ }^{1 *}$, Ahmed S. Al Al-Khafaji ${ }^{1}$, Nadia A. Al-Salam², Tuqa R. Alrobaee ${ }^{1}$ \\ ${ }^{1}$ Faculty of Physical Planning, University of Kufa, Al-Najaf 54001, Iraq \\ ${ }^{2}$ Center of Urban and Regional Planning for Postgraduate, University of Baghdad, Baghdad 10071, Iraq \\ Corresponding Author Email: Ahmeda.hanash@uokufa.edu.iq
}

https://doi.org/10.18280/ijsdp.160606

Received: 25 July 2021

Accepted: 7 September 2021

\section{Keywords:}

urban transformation, traditional cities, crossing, sustainability indicators, philosophical approaches

\begin{abstract}
The topic of urban transformations has attracted the attention of researchers as it is one of the basic issues through which cities can be transformed towards sustainability. A specific level of transformation levels according to a philosophical concept known as a crossing. This article has relied on a specific methodology that aims to find a new approach for urban transformation based on the crossing concept. This concept derives from philosophical entrances based on the concepts of (being, process, becoming, and integration). Four levels have been for the crossing are (normal, ascending, leap, and descending). Each of these levels includes specific characteristics that distinguish it. The results showed that there is no descending crossing in the study area and that four indicators that have achieved leap crossing are: (coverage ratio, compactness, Effectiveness of the pedestrian and bicycle movement, and proximity. As for ascending crossing achieved in three indicators are: mix land use, blocks' length, and connectivity, as for normal crossing achieved in three indicators are: diversity of building heights, population density, and housing density. These results help in making the planning decision to transform traditional Karbala city into a sustainable city, by giving priority in development to the indicators that have achieved ascending crossing because it takes less time and effort to reach the leap crossing in comparison with indicators that have achieved normal crossing.
\end{abstract}

\section{INTRODUCTION}

The phenomenon of urban transformations has occupied the attention of many specialists and researchers, including urban planners, designers, geographers, economists...etc. Especially in the middle of the twentieth century, and considering it as one of the modern phenomena that can be easily observed from its quantitative appearance in our cities today through two things: The first is the growth of the population un their size and number, and the number of cities and urban environments. The second is represented in the forces that push the population from the countryside to the city through the different forces of attraction known as migration. Therefore, it is necessary to study and clarify the impact and influence of urbanization instead of revealing the main motive in this, which is the industrial revolution, where urbanization is considered a product of this revolution. Responsible for its emergence, distribution, and size, as a result of the diverse, complex, positive, and negative changes created and left by the phenomenon of urbanization, it became the focus of researchers' attention in many scientific fields, which led to the emergence of Many kinds of research and studies related to urbanization, its problems, and future effects [1].

Urban transformation can be defined as a series of processes that occur in the urban environment as a result of material motives [2], during which interactions take place in the urban environment that result in changes in the area, shape, and structure of the city to reach an urban system that provides social justice as a primary goal for these interactions [3]. Therefore, it means reshaping the urban environment according to the requirements of the civilization development, urban, and population growth [4]. The urban transformation also reflects the changes that have occurred in the city over time, as the historical aspect of the city occupies an important role in understanding the nature of the urban fabric and the various events that occur in it [5]. Thus, the transformation reflects how people live throughout the ages, which have a major role in shaping housing and religious, economic, and social institutions in response to their requirements and their development over time [6].

The modern construction methods have changed the urban features of the traditional city, by creating modern patterns of high buildings (the global style) and disparate forms that do not correspond and do not harmonize with the human scale of the urban fabric. It was dominated by minarets and domes, for example, in Islamic cities, so the skyline appeared zigzag without regularity or stability, and modern materials affected the change of its features, as buildings with wide glass facades and smooth concrete appeared, so the city became a motley collection of buildings and this is the product of continuous interaction Between industry and modern technologies of this era, and thus the traditional city lost harmony and integration between the individual subjectivity of the building and the urban formation as a whole, and the city became a collection and accumulation of different buildings, cars, and people almost separated from the urban center in which it grew. With 
the emergence of the network system in the planning and composition of cities as a global pattern, the vehicle has become the common factor between contemporary cities in its form, whether in its area or urban structure These cities were designed according to the physical view with the participation of the vehicle and modern building materials (cement and iron), which lost the sensory relationship between the container and the content. The functional relationship between the different areas are affected by the dynamics of movement between and within these areas, as well as the relationship between the scale generated by human movement and the scale generated by the movement of the car. It culminates in absolute space, where highways extend out of cities. The measurement of the transformation in the urban structure depends on the foundations from which this change is measured, which in essence depends on the reasons on which the city arose and the factors that contributed to its growth. Therefore, the change may be positive or negative $[7,8]$.

The traditional city is close in some of its characteristics with the sustainable city, the most prominent of these characteristics are diversity, density, and accessibility. This provides an opportunity to transform it into a sustainable city. The transformation towards sustainable cities is a strategic goal pursued by many cities around the world. Many specialists and decision-makers are discussing how this transformation could happen.

Hölscher and Frantzeskaki [8] presented three different and interrelated theoretical perspectives to achieve transformation in cities. These perspectives are represented by the transformation in, of, and by cities. These transformations depend on several factors. The first factor is the fixed city system represented by buildings. open spaces, transportation networks, and urban activities resulting from them. The second factor is the changing city system represented by the social, economic, and ecological dimensions. The third factor is the institutions, the administrative system, and the local government, which greatly affects the policies and programs and their implementation in cities to achieve transformation. This study suggested that the transformation process should be carried out by choosing an integrated approach that includes all three points of view to achieve a correct and beneficial transformation [9].

Pavel and Jucu [10] focused on clarifying the urban transformations that the Timisoara city experienced and clarifying the constant cultural characteristics that formed the city and made it an urban icon. As the urban identity of the city made it have a clear imprint in every era and made it the capital of European culture. The study relied on a descriptive and quantitative analysis of the effective indicators that achieved the preservation of the city characteristics to develop a general framework for preserving the cultural heritage in cities.

Gün et al. [11] explained the role of conflicts like earthquakes and floods in the urban transformations process in Istanbul city. The study called for adopting participatory planning that relies on technology, information, and techniques. The study showed that stakeholders have a crucial role in determining development trends and urban practices. The study aimed to diagnose and address weaknesses in the urban transformation process, and build a new participatory planning model for urban transformation.

In their study published in 2021, Mikelsone et al., dealt with the urban transformation concept to achieve urban sustainability and tried to present a new approach that includes social, technological, and environmental aspects in achieving transformations. The study aims to find out how urban transformation can achieve economic development in light of the outbreak of the COVID-19 epidemic and economic pressures [12]

Knippschild and Zöllter [13] focused on urban transformations in the Görlitz city, in eastern Germany, which is one of the cities that suffer from decay and decline in its urban structure, despite the presence of components such as heritage areas. The study created a new tool by creating a matrix to assess and test urban transformations that would support urban renewal and conservation decisions. This tool aims to revitalize the stock of buildings in the historical areas protected by the Heritage Buildings Preservation Law, which would contribute to increasing the economic activity of the city as a whole.

Nahiduzzaman et al. [14] dealt with the urban transformations that would transform the city into a smart city. The study showed that the transformation towards smart cities would increase economic efficiency through the adoption of electronic commerce, as well as reduce traffic momentum on transport networks and provide ease of communication with remote marginal areas. This change may cause a transform in the urban structure over time.

Table 1. Classification of the works of literature

\begin{tabular}{|c|c|}
\hline Researchers & Classification \\
\hline $\begin{array}{c}\text { Hölscher \& } \\
\text { Frantzeskaki, } 2021\end{array}$ & $\begin{array}{l}\text { It presented the programs and policies through which urban transformations can take place, depending on the critical } \\
\text { factors in achieving the transformation in a meaningful and correct manner. }\end{array}$ \\
\hline Gün et al, 2021 & $\begin{array}{l}\text { explained the role of conflicts like earthquakes and floods in the urban transformations process and build a new } \\
\text { participatory planning model for urban transformation }\end{array}$ \\
\hline Pavel \& Jucu, 2021 & $\begin{array}{l}\text { It focused on cities containing cultural and heritage characteristics that can contribute significantly to achieving } \\
\text { economic returns, attracting tourists, and accelerating the transformation process in cities. }\end{array}$ \\
\hline $\begin{array}{l}\text { Mikelsone et al, } \\
2021\end{array}$ & $\begin{array}{l}\text { It dealt with the role of modern technological uses, awareness, and societal preparedness in light of the COVID-19 } \\
\text { pandemic, which may play a major role in urban transformations, given that the concept of mobility and social } \\
\text { interaction differed from what was previously known. }\end{array}$ \\
\hline $\begin{array}{l}\text { Knippschild \& } \\
\text { Zöllter, } 2021\end{array}$ & $\begin{array}{l}\text { It focused on preservation laws and adherence to them that would increase the heritage stock of cities, as this could } \\
\text { contribute significantly to the transformation of the city and the improvement of its physical structure. }\end{array}$ \\
\hline $\begin{array}{l}\text { Nahiduzzaman et al. } \\
2021\end{array}$ & $\begin{array}{l}\text { It explained the role of electronic commerce in changing the concept of urban space, as this allows shifting towards } \\
\text { smart cities, which can be highly economically efficient, and achieve a city free of congestion and pollution. }\end{array}$ \\
\hline Farhan e & $\begin{array}{l}\text { The study relied on the approach of preserving heritage buildings and making the city resilient in the face of negative } \\
\text { changes that may occur in the spatial structure as it may negatively affect the social, economic, and environmental } \\
\text { components of cities. }\end{array}$ \\
\hline
\end{tabular}


Farhan et al. [15] dealt with urban transformations in AnNajaf city - Iraq because this city contains a unique architectural heritage and is a destination for millions of people. The study aimed to develop a new approach and vision to preserve the architectural heritage to counteract the negative changes in the spatial structure. The study found that religious, political, and environmental factors have a decisive role in the urban transformation of the city.

Previous studies dealt with important and diverse aspects of urban transformations, as some of them focused on transformations in cities with cultural heritage and the others focused on transformations towards smart cities or sustainable cities. Previous studies suggested different points of view and identified important factors to explain the transformation concept. See Table 1.

Our study differs from previous studies with an important knowledge addition, which is determining the level of the urban transformation in light of the shift towards urban sustainability. In this regard, the research will address the main theoretical concepts represented in the characteristics of traditional cities, as traditional cities include some indicators that they share with indicators of the sustainable city, which may contribute to its urban transformation. Then the research moves to define and clarify urban sustainability indicators in detail. Finally, the research deals with the concept of urban transformations by employing a philosophical concept called transit through which the level of transformations in the spatial structure is determined.

\section{MATERIALS AND METHODS}

\subsection{Traditional city}

The traditional city was formed around the mosque as its main focus. The traditions were reflected in the characteristics of the city, which made it enduring to our present time and can be summarized as follows:

\subsubsection{Variety}

The difference of land uses in the traditional city was built based on the integration between mundane components within religious beliefs and spiritual aspects. The city was characterized by a mixing of land uses between religious, governmental, commercial, and spaces [16]. In addition, the shapes of the spaces are varied, as the space narrows and tortuous at one time and widens and straightens at another [17].

\subsubsection{Compactness and environmental adaptation}

Compactness is one of the important concepts that influenced traditional city planning. It was characterized by the continuity and expansion of the space, to show the city as a connected and interconnected space characterized by the difficulty of dividing it. Therefore, the structure of the city was compact and continuous horizontally [18]. There are no towers in the traditional city, due to the need to highlight the lighthouses and domes to appear clearly in the skyline of the city [19]. The compactness is a response to the hot and dry climate of the city to increase its adaptability. This adaptation is evident from the presence of internal courtyards in residential units, and the hierarchy in planning city spaces as well as winding streets [20].

\subsubsection{Hierarchy}

It is represented in organizing the spaces in a clear hierarchy from the general to the specific. This is evident at all levels of the urban fabric [21], from the city center to the fabric of neighborhoods and local communities. As can be seen in the gradations of the open middle courtyard and the kinetic axes [22].

The movement system in the city consists of three levels, which are the streets that connect the city to the center, the streets that connect adjacent neighborhoods, and the secondary roads within the local communities, some of which are cul-desacs. This strengthened familiarity, communication, bonding, and social relations among the city's residents [23].

\subsection{The sustainable city}

Several quantitative indicators of sustainable cities are specific to the physical form. These indicators express numerical values against which the sustainability of cities can be measured. It can be summarized as follows:

\subsubsection{Diversity}

Four conditions refer to indispensable for generating diversity in a city:

(1) Mix land use is the main factor that brings diversity. Mixed-use is horizontal and vertical. The land uses are classified as commercial, residential, recreational, institutional, and industrial [24]. The mixed-use with high density has an important role in achieving urban sustainability. The land uses must be homogeneous, thus reducing the distance of access to services and activities [25] It can calculate the mix of land uses by using the Simpson index that ranged by (0-1), where a value close to 1 indicates that the land has a large mix of land uses and vice versa as following:

$$
\text { Simpson index }=1-\sum(\mathrm{n} / \mathrm{N})^{2}
$$

where, $\mathrm{n}$ : the area of each land-use type in (Hectare), $\mathrm{N}$ : the total area in (Hectare).

(2) The blocks are short and the diversions in the streets are frequent with many corners. Average block lengths can be measured by the following formula [26]:

Average block length $=\sum$ link length per unit of area / \# nodes per unit of the area

(3) Diversity of buildings height: this indicator This matter measures land potentials to have different classes of society in the urban fabric based on their socio-economic situations. It can be calculated by entropy index with the same indicates of the Simpson index as the following formula [27]

$$
\left.\mathrm{ENT}=-\left[\sum_{j=1}^{k} P^{j} \ln \left(P^{i}\right)\right] / \ln (k)\right]
$$

where, $\mathrm{k}=$ the number of existing housing patterns

$$
\mathrm{Pj}=\text { the percentage of each type within the urban area. }
$$

\subsubsection{Density and intensification}

Density: is the most common explanation for achieving city sustainability [28]. The number of people for a given area becomes effective for the required interactions and for making urban jobs and activities effective and sustainable. But when 
the density exceeds the acceptable limit, the result is exactly the opposite. Density has several sub-indicators which are:

(1) Population density: It is a demographic measure usually used in studies related to land use and housing planning to measure the average number of people in a specific geographic area in the middle of the year, such as countries, cities, or any populated area, which is measured in-person / hectare. It expresses the suitability of the population to the services of the residential locality [29]. It can be calculated by dividing the population by area.

(2) The housing density: It is one of the most important indicators for measuring the intensity of development in urban areas, as it can be applied at various spatial levels, as it indicates the intensity of development through the relationship between residential use with the rest of the other uses. The housing density can be calculated by the number of housing units divided by area [30].

(3) Coverage ratio: It is the ratio of the land area covered by residential buildings to the total area of land allocated for residential purposes, and does not take height into account, but rather refers to the occupancy rate. For example, when buildings cover $50 \%$ of the land area allocated for housing, it means that $50 \%$ of the land area is open and allocated for external uses, and it is considered a preliminary measure of population density, for example, a building with an area of $1000 \mathrm{~m}^{2}$ can cover a land of the same area by $100 \%$ if it is one floor, and by $50 \%$ if it is two floors, and so on [31].

Coverage ratios =built-up area /total residential area.

(4) Compactness: It expresses the ratio of solids to voids. Compact cities provide shorter distances in travel between residential and work areas. This can be represented by a cylindrical city with a fair distribution of development in all its parts. It can be measured by as following [17]:

$$
\text { Compactness :1- (Sa/S *100) }
$$

where, Sa: overall open spaces in the city

$\mathrm{S}$ : overall built-up area in the city

\subsubsection{Mobility and accessibility}

There is a strong relationship between transportation networks and urban sustainability. Improving connectivity and accessibility to urban areas is a prerequisite. Hence, the transportation network is important at all spatial levels. Good communication using non-motorized media for short trips is important for improving air quality and creating a greater sense of belonging among the population [32]. Its subindicators can be summed up:

(1) The effectiveness of the pedestrian and bicycle movement: this indicator can be measured based on the $\alpha$ index, its value ranges between (0-1), where the high value indicates greater effectiveness of the movement of the tire and bicycles [33]. It can be calculated by the following formula:

$$
\alpha=(\mathrm{e}-\mathrm{v}+1) /(2 v-5)
$$

where, (e) represents the number of segments (linkages) and the number of nodes $(v)$ in the street network respectively, and the $\alpha$ index value ranges between ( $0-1)$ and the higher value represents a high degree of connectivity for the walking and riding network degrees, which means that a person can reach several places by different paths.

(2) Traffic network connectivity: Network connectivity is defined as the extent to which streets connect with a numerical density of intersections, a large number of short links, and a small number of cul-de-sacs. It can be measured by dividing the number of real nodes by unit area, and a higher number indicates more intersections and high connectivity [34]. The preferred limit of R/A is between 150-170 [35].

where, $\mathrm{R}$ represents the number of real nodes in the neighborhood that do not lead to closed streets, $\mathrm{A}$ is the neighborhood area measured in hectares.

(3) Proximity: Provides appropriate and comfortable proximity to the basic needs, facilities, and services [36]. Several studies have determined that the acceptable walking distance that a person travels from his home to service areas is within a quarter of a mile, approximately 400 meters [37].

\subsection{The crossing approach}

Most studies introduce the transformation concept in general without specifying the necessary level of transformation through which the optimal state of transformation can be determined [38]. In this regard, this research relied on a complex philosophical approach, the crossing approach, through which the transformation level can be determined, as this approach consists of the following concepts [39] See Figure 1:

(1) Being: It represents the being of a thing before the changes occurred, as the reality of the traditional citystate before it was transformed into a sustainable city [40].

(2) Process: It represents the time required to transform from a traditional city to a sustainable city [41].

(3) Becoming: It is the transformation from one state or stage to another state or stage, such as the city transformation from the traditional state to the sustainable state [42].

(4) Integration: It is a set of becoming and transformations that lead to development reaching an ideal state, such as the transformation of a traditional city into a sustainable city through multiple stages and becoming [43].

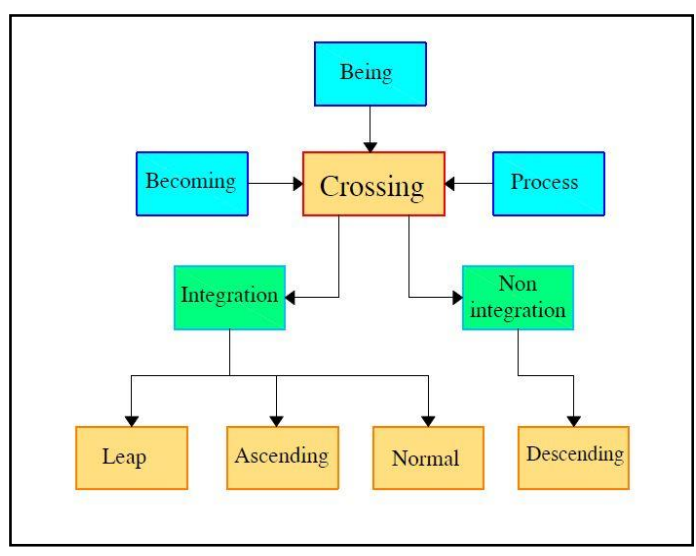

Figure 1. The level of crossing 
This research aims to determine the level of crossing and appropriate strategies for the traditional Karbala city to transform it into a sustainable city. It represents an attempt to suggest a new methodology in the transformation towards sustainable cities by relying on the crossing approach.

The crossing is defined as moving from one place to another via a specific path, or between two sides. It is moving from one status to another or from one point to another, or from one level to another, and from one stage to another. The crossing may be at one frequency or a different pace, and it may move to a better state or move to a worse state. The different relationships between being, process, becoming and integration stages define four levels of crossing, represented by normal crossing, ascending crossing, leap crossing, and descending crossing [44].

The first level is normal crossing: is the movement, change across time and space from one state to another through a single, continuous, permanent frequency and slow.

The second level is the ascending crossing: - where the development escalates, rises, and is integrated if the appropriate tools are available for it, therefore it is not necessary that it be on a single pace, and is intermittent and not continuous.

The third level is leap crossing: It is the greatest that can be reached, as it needs to combine all the capabilities and methodological means for an unusual crossing. It transcends the single-tempo crossing, and the escalating crossing to overcome great difficulties. It represents the crossing level that transfers the process and moves from the present to the future at a very wide pace. It is the most difficult crossing operation, the most important of which is the resistance and the moral determination to overcome obstacles.

The third level is leap crossing: It is the greatest that can be reached, as it needs to combine all the capabilities and methodological means for an unusual crossing. It transcends the single-tempo crossing, and the escalating crossing to overcome great difficulties. It represents the crossing level that transfers the process and moves from the present to the future at a very wide pace. It is the most difficult crossing operation, the most important of which is the resistance and the moral determination to overcome obstacles.

The fourth level is the descending crossing: it is intended as regressive, in which the shift is from a linear logic constant and stable in all its details to non-linear and confused, anomalous and chaotic, then regression and deterioration occur. See Figure 2.

It can be said that crossing levels present four different scenarios for how cities can move towards sustainability through the application of specific strategies for each level and according to the reality of the situation of those cities:

A. Slow transformation $=$ normal crossing requires a long period and limited changes in the urban structure.

B. Intermediate transformation $=$ ascending crossing that requires a moderate period with multiple changes in the urban structure.

C. Rapid transformation = leap crossing requires a short period with rapid and comprehensive changes in all aspects of the urban structure.

D. Negative transformation $=$ descending crossing represents the state of negative changes in the urban structure in a specific period.

This study aims to determine the level of crossing and appropriate strategies for the traditional Karbala city to transform it toward sustainability.

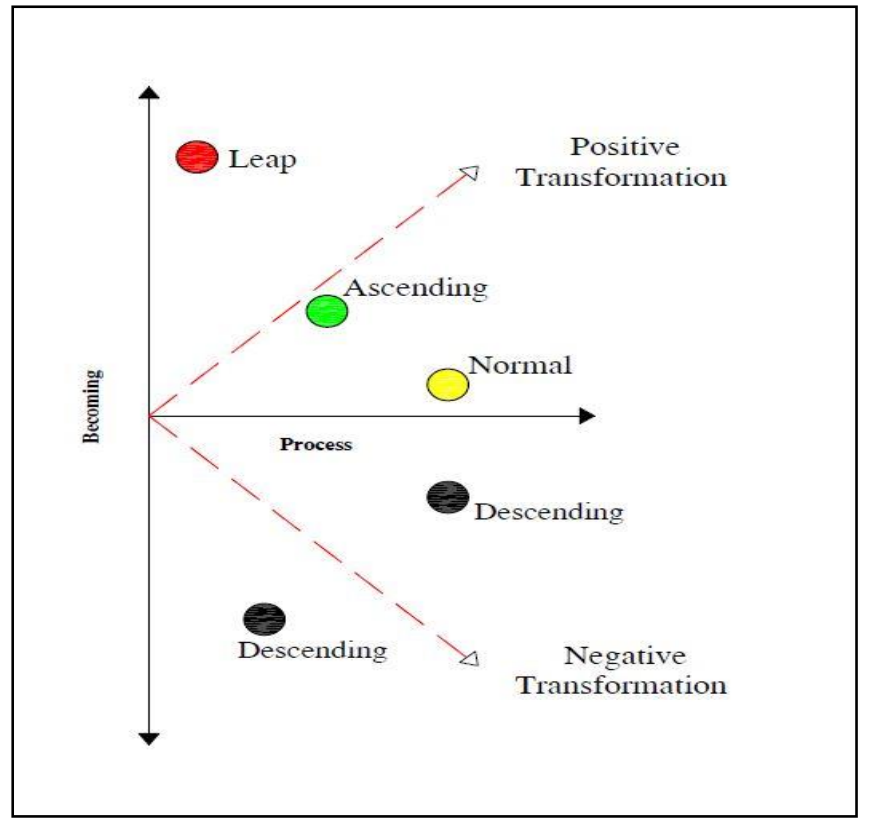

Figure 2. Transformation according to crossing approach

\section{RESEARCH METHODOLOGY}

The research relied on the descriptive approach in the theoretical framework and the quantitative and qualitative analysis approach in the practical framework, by adopting the characteristics of the traditional city and comparing it with the characteristics of sustainable cities. The purpose of this is to find the common points through which urban transformations can be adopted. By defining the main characteristics of traditional cities (diversity, compactness, and environmental adaptation, hierarchy). Which was found to share the main characteristics of sustainable cities (diversity, density \& densification, mobility $\&$ accessibility).

These main characteristics include several indicators that can be measured by many quantitative measures. After that, the research adopted the derivation of a new approach to urban transformations. The research was based on finding a new approach in urban transformations by adopting the philosophical concepts of (being, process, becoming, and integration), and by adopting the integration between them, a complex philosophical concept called crossing was employed. This concept includes four levels, the highest of which is the leap level, followed by the ascending level, followed by the normal level, and the least descending crossing, which represents the negative state of urban transformations being less than the minimum limits of urban sustainability indicators. See Figure 3.

The research depends on the practical side on the quantitative analysis of the traditional city of Karbala in Iraq, and through the use of the GIS application to determine the possibility of crossing to a sustainable city and identifying it within any level of crossing levels in this transformation, the research used to collect information and field visits to the study area as well as data which were collected from the government directorates, and previous studies that dealt with the study of the city.

This study aims to determine the level of crossing and appropriate strategies for the traditional city of Karbala to transform toward sustainability. 


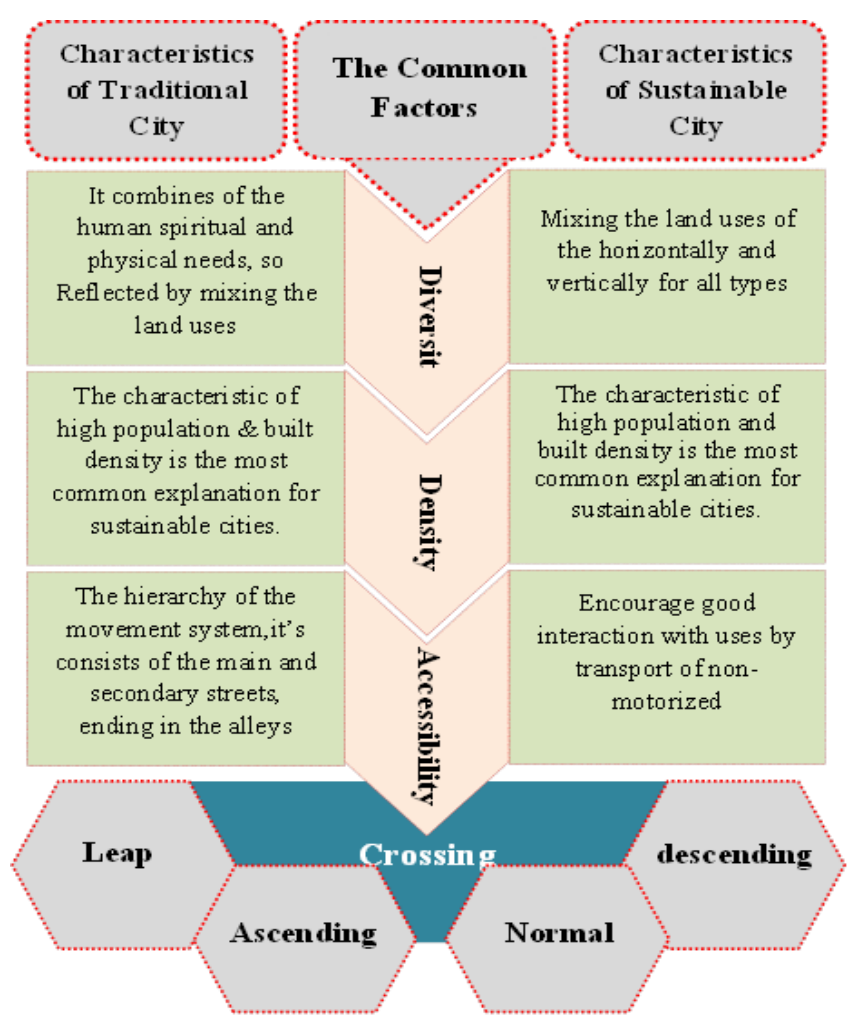

Figure 3. The methodology

\section{CASE STUDY: TRADITIONAL CITY CENTER OF KARBALA}

The Karbala city is the administrative center of the Karbala Governorate, which represents one of the provinces of the Middle Euphrates. It is about $110 \mathrm{~km}$ away from the city of Baghdad, the capital of the Republic of Iraq. As for astrological position are located in $43^{\circ} 25^{\prime}$ latitude and $32^{\circ} 35^{\prime}$ [45] (Figure 4).

The traditional Karbala city represents the center of the contemporary city, and it has preserved many of the characteristics of the traditional city [46]. It represents an important religious center as a result of its containing shrine of Al-Hussein bin Ali, grandson of the Prophet Muhammad, that many people visit for religious tourism [47].

The traditional city center of Karbala is one of the cities with diverse activities, as much as it witnesses tourist activity due to its rich religious and historical elements. Therefore, the economic activities and functions vary, as it possesses the elements of agricultural activity due to the abundance of its orchards, and it contains many factories and industrial facilities. However, the city is predominantly religious and touristic, which is mainly reflected in the sustainability and effectiveness of its economic performance and demographic potentials, growth, and urban transformation [48]. This is reflected in the fact that it is a city with a variety of activities in its functional performance, as it is as much as it is characterized by the manifestations and mechanisms of religious visits to the holy shrine, it also reflects a distinct economic activity due to these events $[49,50]$.

Today, the city of Karbala is had strategic importance and enjoys cultural, historical, and religious authenticity. It also has economic importance due to its material components, economic wealth, and moral value that transcend the borders of the Iraq Republic [51].

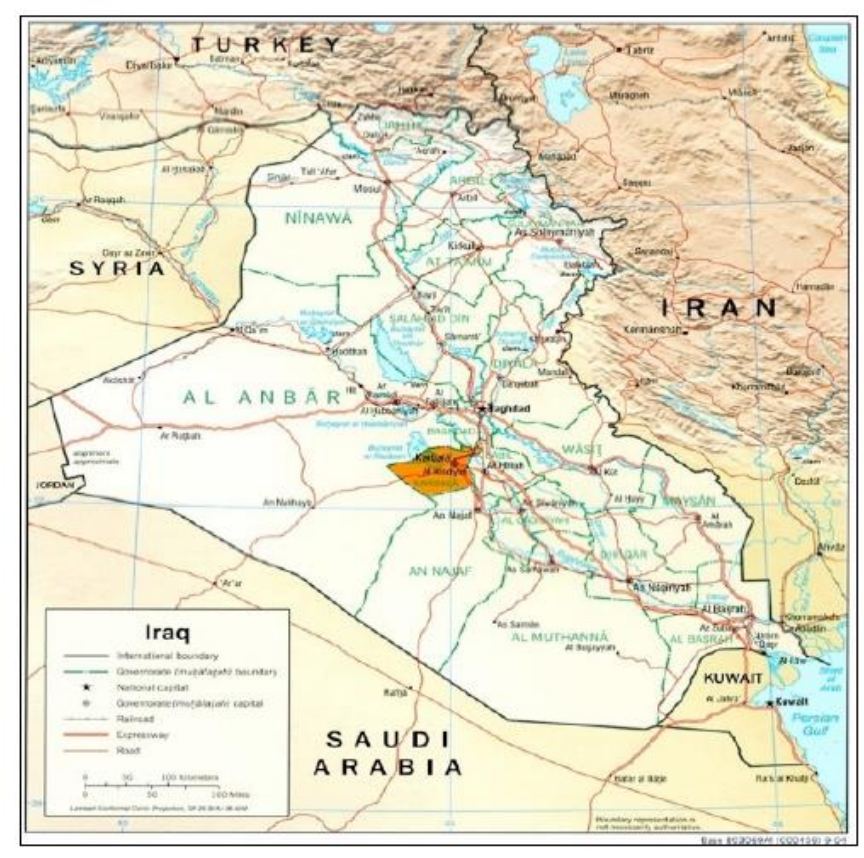

Figure 4. The Geographic location of Karbala governorate

\section{ANALYSIS AND DISCUSSION}

The data used in this part were collected from the relevant government departments represented by represented (Karbala Municipality directorate, Urban Planning directorate in Karbala, Karbala Governorate, Karbala Governorate Council, Karbala Statistics Department, Tourism agency), and the documentation studies for the city of Karbala, and the field survey carried out by the authors, in addition to the use of the application of GIS.

\subsection{Diversity}

For this criterion, the selected indicators are (mixedness of land uses, Block lengths, and diversity of buildings height). This research takes advantage of the application of GIS to calculate the component of the formulas like (Areas of land use, the length of the blocks, number of junctions .... etc.

The mixedness of land uses calculations are based on the Simpson index by determining the area of each land uses by GIS applications, and the result showed for the mixedness of land uses is about (0.66). The value of the diversity index can be considered as a medium value due to the presence of the dominance of residential use in the northwestern and eastern neighborhoods of the city. This means that the urban transformation within an ascending crossing. To improve the level of diversity, the residential use is changed with a mixture of other uses (Figure 5).

As the average blocks' length is based on the formula of the average block length explained previously and their component was calculated in the same way by calculating the total blocks' length and the number of nodes for the area. The result showed that the average blocks' length is about $(163 \mathrm{~m})$. This indicator indicates that the value is slightly greater than the required limits, which indicates that the urban transformation reflects an ascending crossing (Figure 6).

While the diversity of buildings height indicator was characterized by a moderate mix value, where the results of the analysis showed an average value of (0.52) according to 
the equation of the Entropy index that was explained previously. Therefore, the city will give an indicator of urban transformation that reflects a normal crossing (Figure 7).

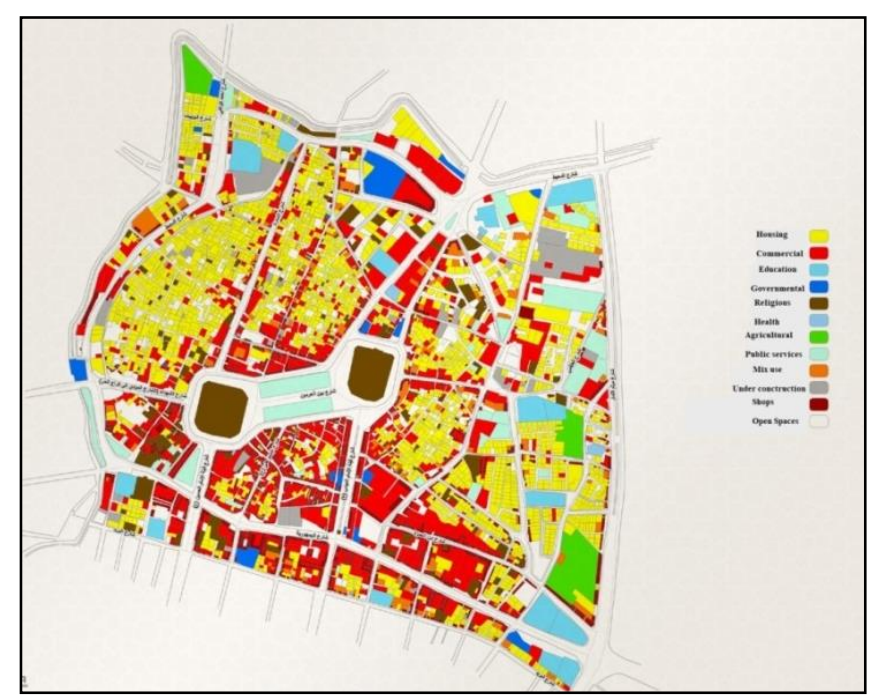

Figure 5. The mixedness of land use

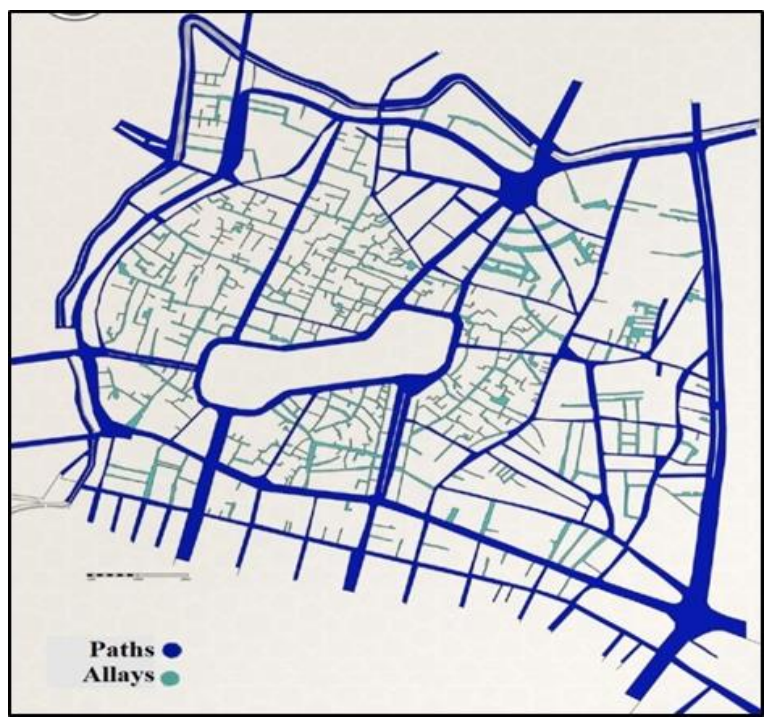

Figure 6. The network of paths and alleys for the case study

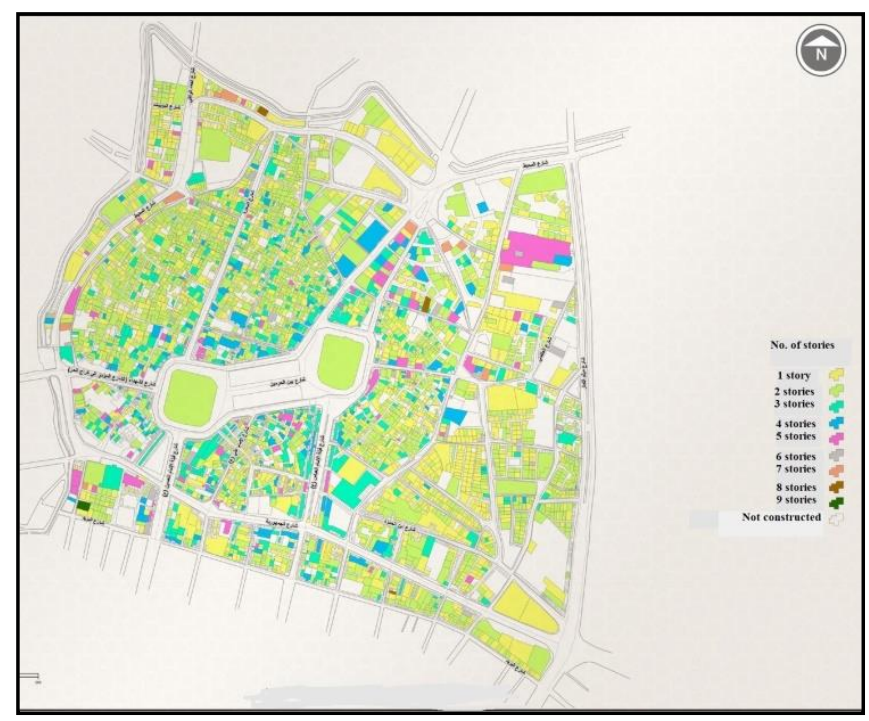

Figure 7. Buildings height mixedness

\subsection{Density}

The density criterion is one of the most factors that formulate the urban structure for the city and to calculate this criterion, four indicators are derived: (population density, housing density, coverage ratio, and compactness) the analysis of these indicators showed the following:

The population density, the analysis for the urban structure for the fabric showed that high value for the population density (343 people/hectare), as a result of the high concentration of population and activities as a result of people's tendency to live near shrines to seek blessings and perform visiting activities, as well as to provide services (commercial and service, etc.) to users. Therefore, the urban transformation shows a normal crossing.

In the same way, the housing density showed a high value of about (62 units/hectare) despite the multiplicity of commercial activities at the expense of residential activities. This high value comes as a result of the small area of housing units, as well as the lack of external spaces (such as gardens and spaces), and on this basis, we noted that the urban transformation shows a normal crossing (Figure 8).

As the coverage area ratio, the buildings in the area are characterized by box designs with a tendency to the appearance of protrusions in the upper floors in the design. The result of the analysis showed that the coverage ratio was high and amounted to about (0.92). Based on what has been analyzed, the urban transformation reflects a normal crossing (Figure 9).

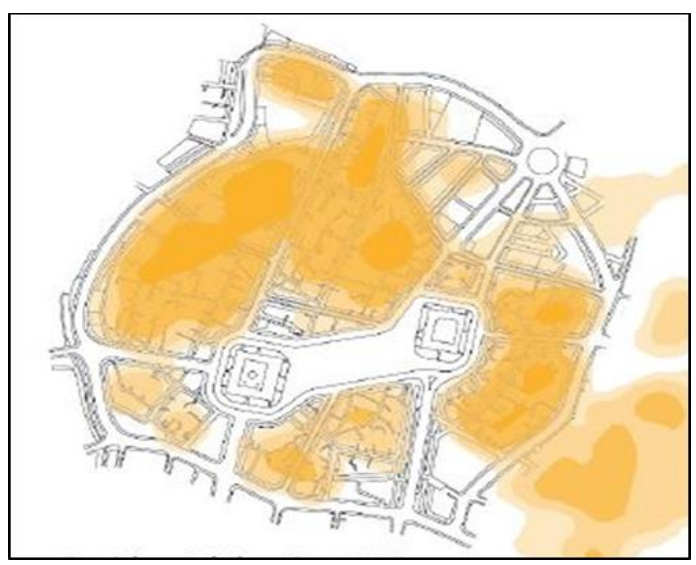

Figure 8. Density concentration

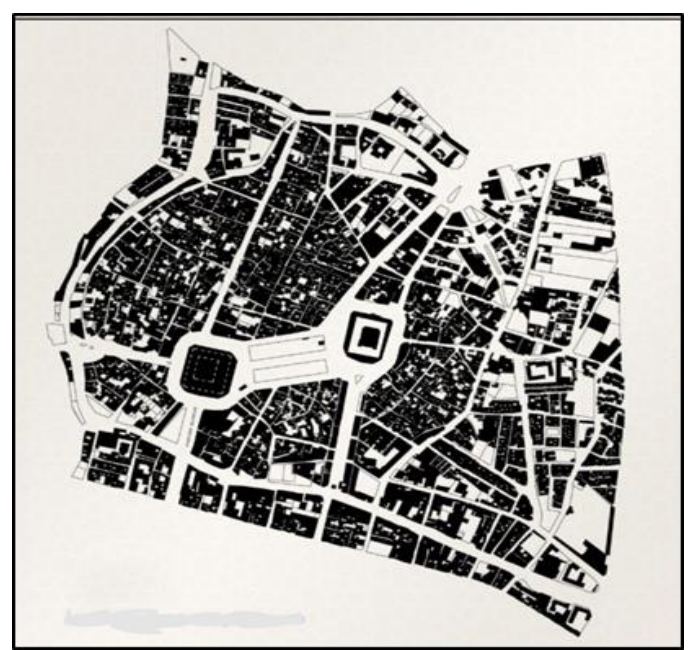

Figure 9. High value for the coverage ratio 
While concerning the compactness, the characteristics of traditional Karbala city was characterized by high compactness in buildings and narrow alleys except for the urban space around the shrine, and the main movement axes, which are mostly intended for pedestrians. On this basis, the value of the compactness was (0.728) so that the urban transformation reflects a leap crossing (Figure 10).

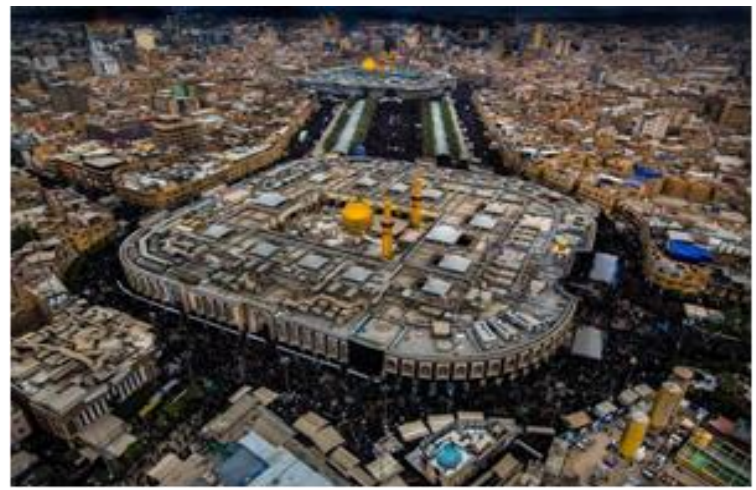

Figure 10. The compactness of the building in the study area

\subsection{Accessibility and mobility}

The nature of the movement network for the cities plays a great role in the distribution of the activities, and organize the relation between land uses and transport networks. It can be said that accessibility is a measure of the performance of the transport and development plans. For this criterion were derived three indicators for measuring the effectiveness of it that was explained previously (effectiveness of the pedestrian and bicycle, connectivity, and proximity) (Figure 10).

The effectiveness for pedestrians and bicycles was calculated from the $\alpha$ index shows a high degree of accessibility for the pedestrian specifically as a result of the availability of safety elements for pedestrians. The cars are not allowed to enter the traditional Karbala city, except for environmentally friendly electric cars, which are used for the elderly. At the same time, people prefer to walk in the city to feel pleasure and psychological comfort, also the absence of long paths (the paths are relatively short) to reach the destinations for visitors. The trip is directed through the view of the prominent dome, which acts as an attraction that encourages people psychologically to walk to reach the destination. On this basis, we noted that the urban transformation shows a leap crossing (Figure 11).

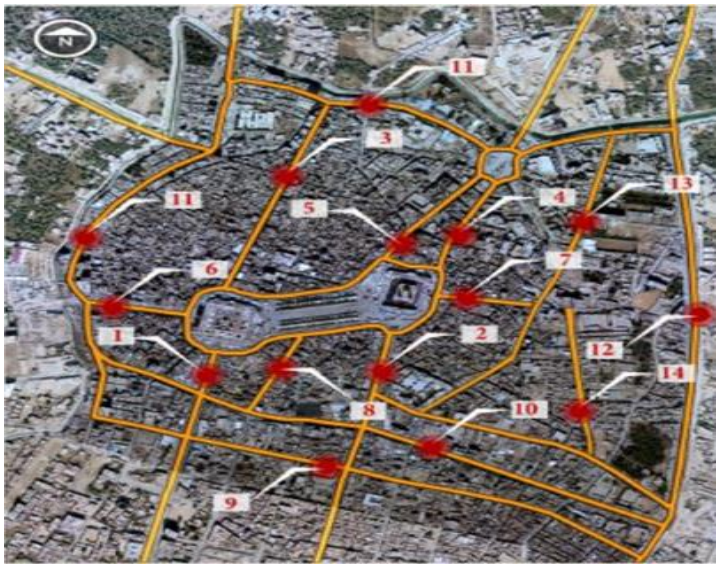

Figure 11. The main axes in the study area
While the proximity indicator as it is known, the increase in it will contribute mainly to shortening the distance that users make to perform their activities with high efficiency, it is an indicator of the quality of life in the urban area. The average distance for the people who live in the city is about $(680 \mathrm{~m})$, where the convergence between the activities and their concentration in a specific area within the city contributed to making the average distance within the comfortable range for its performance. On this basis, the indicator of urban transformation reflects a leap crossing (Figure 12).

Based on the analysis and discussion, the results show us the levels of the crossing as shown in Table 2, and Figure 13 shows the final result of the calculation values for the indicators and the levels of crossing according to the proposed methodology.

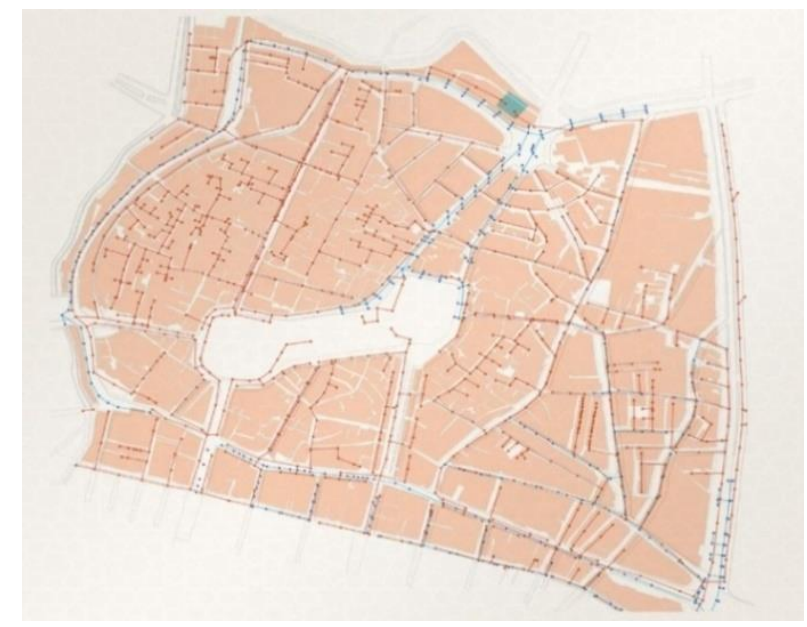

Figure 12. The connectivity in the study area
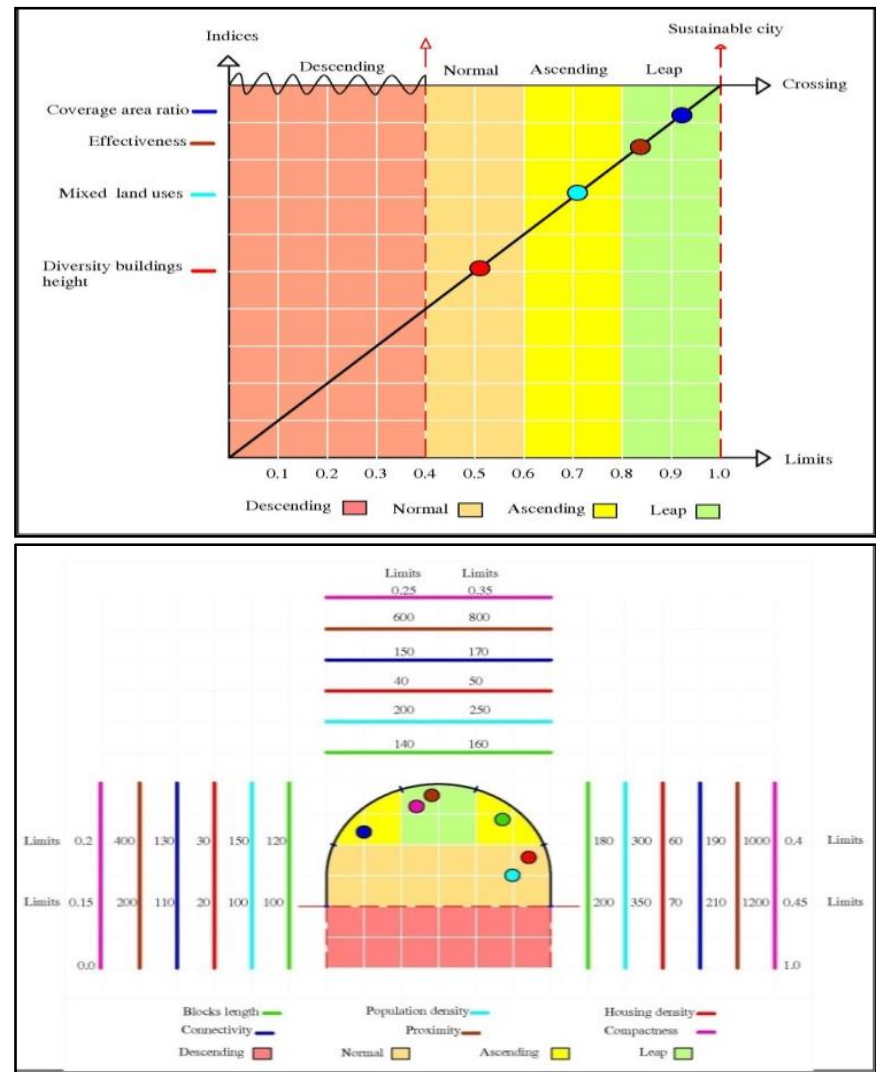

Figure 13. The result of the calculation of the crossing indicator for in study area 
Table 2. The final result of the calculation values for the indicators and the type of the crossing according to the proposed methodology For Karbala city center

\begin{tabular}{cccccccc}
\hline Indicators & Limits & $\begin{array}{c}\text { Leap } \\
\text { crossing }\end{array}$ & $\begin{array}{c}\text { Ascending } \\
\text { crossing }\end{array}$ & $\begin{array}{c}\text { Normal } \\
\text { crossing }\end{array}$ & $\begin{array}{c}\text { Descending } \\
\text { crossing }\end{array}$ & $\begin{array}{c}\text { Crossing level in the case } \\
\text { study }\end{array}$ \\
\hline Mix land use & $0-1$ & $1-0.8$ & $0.8-0.6$ & $0.6-0.4$ & $0.4-0$ & $0.66($ Ascending) \\
\hline Blocks' length & $100-200$ & $140-160$ & $\begin{array}{c}160-180 \\
120-140\end{array}$ & $\begin{array}{c}180-200 \\
120-100\end{array}$ & $100>\mathrm{X}>200$ & 169 (Ascending) \\
\hline Diversity of building heights & $0-1$ & $1-0.8$ & $0.8-0.6$ & $0.6-0.4$ & $0.4-0$ & $0.52(\mathrm{Normal})$ \\
\hline Population density & $100-350$ & $200-250$ & $\begin{array}{c}150-200 \\
250-300\end{array}$ & $\begin{array}{c}300-350 \\
100-150\end{array}$ & $100>\mathrm{X}>350$ & 343 (Normal) \\
\hline Housing density & $20-70$ & $40-50$ & $\begin{array}{c}50-60 \\
30-40\end{array}$ & $\begin{array}{c}60-70 \\
20-30\end{array}$ & $20>\mathrm{X}>70$ & 62 (Normal) \\
\hline Coverage ratio & $0-1$ & $1-0.8$ & $0.8-0.6$ & $0.6-0.4$ & $0.4-0$ & 0.92 (Leap) \\
\hline Compactness & $0-1$ & $0.75-0.65$ & $\begin{array}{c}0.65-0.60 \\
0.80-0.75\end{array}$ & $\begin{array}{c}0.60-0.55 \\
0.85-0.80\end{array}$ & $0.55-1$ & $0.85-0$ & 0.728 (Leap) \\
\hline $\begin{array}{c}\text { Effectiveness of the } \\
\text { pedestrian and bicycle }\end{array}$ & $0-1$ & $1-0.8$ & $0.8-0.6$ & $0.6-0.4$ & $0.4-0$ & 0.83 (Leap) \\
\hline Connectivity & $110-210$ & $150-170$ & $\begin{array}{c}130-150 \\
170-190\end{array}$ & $\begin{array}{c}110-130 \\
190-210\end{array}$ & $110>\mathrm{X}>210$ & 132 (Ascending) \\
\hline Proximity & $200-1200$ & $600-800$ & $\begin{array}{c}800-1000 \\
400-600\end{array}$ & $\begin{array}{c}1000-1200 \\
200-400\end{array}$ & $200>\mathrm{X}>1200$ & 680 & $(\mathrm{Leap})$ \\
\hline
\end{tabular}

\section{CONCLUSION}

This paper deals with a new approach in dealing with traditional cities to transform them into sustainable cities. This new approach was based on a complex philosophical concept, the crossing concept, which contains four different levels. Knowing the level at which the traditional city is located will contribute to knowing the indicators that require a great time and effort, or those that require less time and effort. Subsequently, priority is set in dealing with these indicators. This approach will help urban planners, urban designers, and decision-makers in making decisions that ensure the development of cities for the better, and to bring them to the acceptable limits of the approved standards within appropriate periods.

Descending crossing constitutes a major obstacle to the development and transformation of sustainable cities because it is outside the limits of the standard that create the quality of the urban environment. It is good that most indicators in the study area were within the leap crossing level, which facilitates the transformation process towards sustainability. With the need to pay attention to the indicators that fall at the normal crossing level, this can be done through the development of indicators located in the ascending crossing level, such as transferring a percentage of the residential land uses consisting of one or two floors to commercial, cultural and recreational uses with multi-story, which contribute to reducing residential and population densities and achieving diversity in building heights. This, in turn, will transform the indicators at the ascending crossing level into the leap level, and the indicators at the normal crossing level into the ascending crossing.

This research gives broader future horizons in studying urban transformations by adopting new concepts through which new and diverse approaches can be found to achieve sustainable cities. Future studies are examining the relationship of the effect of the urban form in achieving sustainability or identifying the most suitable urban forms for sustainability. It can also look at the nature of the transformations that occur in urban forms and their time ranges, and which of them may be the closest to achieving sustainability and trying to determine the appropriate levels of transit for different urban environments.

\section{REFERENCES}

[1] Dabbour, L.M. (2021). Morphology of quarters in traditional Arab Islamic city: A case of the traditional city of Damascus. Frontiers of Architectural Research, 10(1): 50-65. https://doi.org/10.1016/j.foar.2020.11.004

[2] Montgomery, M.R. (2008). The urban transformation of the developing world. Science, 319(5864): 761-764. http://doi.org/10.1126/science.1153012

[3] Maassen, A., Galvin, M. (2019). What does urban transformation look like? Findings from a Global Prize Competition. Sustainability, 11(17): 4653. https://doi.org/10.3390/su11174653

[4] Williams, J.J. (2000). South Africa: Urban transformation. Cities, 17(3): 167-183. http://dx.doi.org/10.1016/S0264-2751(00)00012-3

[5] Németh, J., Langhorst, J. (2014). Rethinking urban transformation: Temporary uses for vacant land. Cities, 40: 143-150. https://doi.org/10.1016/j.cities.2013.04.007

[6] Thorns, D.C. (2017). The Transformation of Cities: Urban Theory and Urban Life. Macmillan International Higher Education.

[7] McPhearson, T., Iwaniec, D.M., Bai, X. (2016). Positive visions for guiding urban transformations toward sustainable futures. Current Opinion in Environmental Sustainability, 22: 33-40. https://doi.org/10.1016/j.cosust.2017.04.004

[8] Hölscher, K., Frantzeskaki, N. (2021). Perspectives on urban transformation research: Transformations in, of, and by cities. Urban Transformations, 3(1): 1-14. https://doi.org/10.1186/s42854-021-00019-z

[9] Al-Khafaji, A.S., Al-Salam, N.A., Alrobaee, T.R. (2021). The cognition role to understanding planning and architectural production. Civil Engineering Journal, 7(7): 1125-1135. https://doi.org/10.28991/cej-2021-03091715

[10] Pavel, S., Jucu, I.S. (2020). Urban transformation and cultural evolution of post-socialist European cities. The case of Timisoara (Romania): From 'little Vienna'urban 
icon to European capital of culture (ECoC 2021). City, Culture and Society, 20: 100296. https://doi.org/10.1016/j.ccs.2019.100296

[11] Gün, A., Pak, B., Demir, Y. (2021). Responding to the urban transformation challenges in Turkey: A participatory design model for Istanbul. International Journal of Urban Sustainable Development, 13(1): 32-55. https://doi.org/10.1080/19463138.2020.1740707

[12] Mikelsone, E., Atstaja, D., Koval, V., Uvarova, I., Mavlutova, I., Kuzmina, J. (2021). Exploring sustainable urban transformation concepts for economic development. Studies of Applied Economics, 39(5). https://doi.org/10.25115/eea.v39i5.5209

[13] Knippschild, R., Zöllter, C. (2021). Urban regeneration between cultural heritage preservation and revitalization: Experiences with a decision support tool in Eastern Germany. $\quad$ Land, $10(6)$ : 547. https://doi.org/10.3390/land10060547

[14] Nahiduzzaman, K.M., Holland, M., Sikder, S.K., Shaw, P., Hewage, K., Sadiq, R. (2021). Urban transformation toward a smart city: An E-commerce-induced pathdependent analysis. Journal of Urban Planning and Development, $\quad$ 147(1): 04020060. https://doi.org/10.1061/(ASCE)UP.1943-5444.0000648

[15] Farhan, S., Akef, V., Nasar, Z. (2020). The transformation of the inherited historical urban and architectural characteristics of Al-Najaf's Old City and possible preservation insights. Frontiers of Architectural Research, 9(4): 820-836. https://doi.org/10.1016/j.foar.2020.07.005

[16] Amany, A.K., Ebraheem, M.A. (2020). Comparative Analysis of land use and urban growth modeling using geomatics technology (city of Najaf-Iraq). IOP Conference Series: Materials Science and Engineering, 881(1): 012023 . https://doi.org/10.1088/1757$899 \mathrm{X} / 881 / 1 / 012023$

[17] Hataminejad, H., Pourahmad, A., Zayyari, K.A., Behboodi, M.H. (2019). Spatial dynamics of islamic city based on complexity theory; case study: Tehran central district. Journal of Studies on Iranian Islamic City, 9(37): 41-52.

[18] Al-Khafaji, A.S.J., Al-Salam, N.A.M. (2018). Measurement of urban sprawl and compactness characteristics Nasiriyah city - Iraq as case study. International Journal of Civil Engineering and Technology (IJCIET), 9(9): 335-343.

[19] Al-Shouk, N.D., Al-Khfaji, A.S. (2018). Toward sustainable compact city: (study in convert traditional najaf city to sustainable compact city). KnE Engineering, 3(4): 167-192. https://doi.org/10.18502/keg.v3i4.2168

[20] Al-Mosawy, S.K., Al-Jawari, S.M., Al-Jaberi, A.A. (2020). The effect of urban form on temperature for hot arid zones. The case study of Baghdad, Iraq. IOP Conference Series: Earth and Environmental Science, 459: $062109 . \quad$ https://doi.org/10.1088/1755$1315 / 459 / 6 / 062109$

[21] lnaim, M.M. (2020). The hierarchical order of spaces in Arab traditional towns: The case of Najd, Saudi Arabia. World Journal of Engineering and Technology, 8(3): 347-366. https://doi.org/10.4236/wjet.2020.83027

[22] Alimi, A. (2021). Comparative study of the hierarchy of entry in the mosques of Tabriz Grand Bazaar and Qaysari Bazaar of Isfahan. Haft Hesar Journal of Environmental
Studies,

9(34):

https://doi.org/10.29252/hafthesar.9.34.4

[23] Jamei, E., Ahmadi, K., Chau, H.W., Seyedmahmoudian, M., Horan, B., Stojcevski, A. (2021). Urban design and walkability: Lessons learnt from iranian traditional cities. Sustainability, 13(10): https://doi.org/10.3390/su13105731

[24] Farhan, S.L., Antón, D., Akef, V.S., Zubaidi, S.L., Hashim, K.S. (2021). Factors influencing the transformation of Iraqi holy cities: The case of Al-Najaf. Scientific Review Engineering and Environmental Sciences, 30(2): 365-375. https://doi.org/10.22630/PNIKS.2021.30.2.31

[25] Bordoloi, R., Mote, A., Sarkar, P.P., Mallikarjuna, C. (2013). Quantification of land use diversity in the context of mixed land use. Procedia-Social and Behavioral Sciences, $\quad$ 104(0): 563-572. https://doi.org/10.1016/j.sbspro.2013.11.150

[26] Tresidder, M. (2005). Using GIS to measure connectivity: An exploration of issues. Portland State University: Field Area Paper.

[27] Song, Y., Knaap, G.J. (2004). Measuring the effects of mixed land uses on housing values. Regional Science and Urban Economics, 34(6): 663-680. https://doi.org/10.1016/j.regsciurbeco.2004.02.003

[28] Alrobaee, T.R. (2021). Measuring spatial justice indices in the traditional islamic cities by using GIS, an-Najaf Holy City, Iraq a case study. Journal of Geoinformatics \& Environmental Research, 1(2): 59-69. https://doi.org/10.38094/jgier1220

[29] Mills, E.S., Tan, J.P. (1980). A comparison of urban population density functions in developed and developing countries. Urban Studies, 17(3): 313-321. https://doi.org/10.1080/00420988020080621

[30] Hasse, J., Lathrop, R.G. (2003). A housing-unit-level approach to characterizing residential sprawl. Photogrammetric Engineering \& Remote Sensing, 69(9): 1021-1030. https://doi.org/10.14358/PERS.69.9.1021

[31] Bender, B. (1981). Urban housing density and the price of housing services. Journal of Urban Economics, 9(1): 80-84. https://doi.org/10.1016/0094-1190(81)90049-8

[32] Paramita, B., Fukuda, H. (2014). Public housing in Bandung an assessment and approaches through urban physics. Advanced Materials Research, 935: 273-276. https://doi.org/10.4028/www.scientific.net/AMR.935.27 3

[33] Al-Jaberi, A., Al-Khafaji, A., Ivankina, N., Al-Sawafi, M. (2019). The idea of pedestrian pockets as a key for successful transit-oriented development for Najaf cityRepublic of Iraq. IOP Conference Series: Materials Science and Engineering, 698(3): 033029. https://doi.org/10.1088/1757-899X/698/3/033029

[34] Alrobaee, T., Al-Kinani, A. (2019). Place dependence as the physical environment role function in the place attachment. Paper presented at the IOP Conference Series: Materials Science and Engineering. https://doi.org/10.1088/1757-899X/698/3/033014

[35] Al-jaberi, A.A. (2021). Developing a transit-oriented development research methodology for the cities of Najaf and Kufa, republic of Iraq. Architecton: Proceedings of Higher Education/Architecton: Izvestia Vuzov, 1(73): 1-15. https://doi.org/10.47055/1990-41262021-1(73)-16 
[36] Mecredy, G., Pickett, W., Janssen, I. (2011). Street connectivity is negatively associated with physical activity in Canadian youth. International Journal of Environmental Research and Public Health, 8(8): 33333350. https://doi.org/10.3390/ijerph8083333

[37] Gil Solá, A., Vilhelmson, B. (2019). Negotiating proximity in sustainable urban planning: A Swedish case. Sustainability, 11(1): 31 https://doi.org/10.3390/su11010031

[38] Alrobaee, T., Al-Khafaji, A., Al-Jawari S. (2021). Measurement of physical environment characteristics for supporting transit-oriented development areas for the Kufa city-Iraq. International Journal of Scientific \& Engineering Research, 12(1): 635-642.

[39] Al-jaberi, A. (2014). Prigogine's Caius philosophy: Origin and development: An analytical study of the science of the unexpected The House and Library of Insights Lebanon, Beirut-Lebanon.

[40] Leuenberger, M. (2021). What is the point of being your true self? A genealogy of essentialist authenticity. Philosophy, 96(377): 409-431.

[41] Mesoudi, A. (2021). Cultural selection and biased transformation: Two dynamics of cultural evolution. Philosophical Transactions of the Royal Society B, 376(1828). https://doi.org/10.1098/rstb.2020.0053

[42] Malafouris, L. (2021). Mark making and human becoming. Journal of Archaeological Method and Theory, 28(1): 95-119. https://doi.org/10.1007/s10816020-09504-4

[43] Pope, E.M., Nicolaides, A. (2021). Becoming Thou as transformation in interfaith dialogue. International Journal of Lifelong Education, 40(2): 115-128. https://doi.org/10.1080/02601370.2021.1882596

[44] Haddad, A.T.H. (2017). Architecture according to philosophy of crossing (al-uobor) architecture concept according to Al-Jabari philosophical model. The Iraqi
Journal of Architecture and Planning, 16(4): 38-53.

[45] Alrawi, A.K. (2020). Policies of sustainable transportation in the holy city of Karbala. Journal of Southwest Jiaotong University, 55(2). https://doi.org/10.35741/issn.0258-2724.55.2.16

[46] Farhan, S.L., Abdelmonem, M.G., Nasar, Z.A. (2018). The urban transformation of traditional city centers: Holy Karbala as a case study. ArchNet-IJAR: International Journal of Architectural Research, 12(3): 53. http://dx.doi.org/10.26687/archnet-ijar.v12i3.1625

[47] Khorsand, R., Alalhesabi, M., Kheyroddin, R. (2020). Redefining the concept of the 24-hour city and city nightlife for holy cities, with the use of Islamic instructions: A Case study of the holy city of Karbala. IOP Conference Series: Materials Science and Engineering, 671(1): 012116.

[48] Al-Jawari, S.M., Al-Mosawy, S.K., Al-Jaberi, A.A., AlBaghdadi, A.N. (2020). Strategic analysis of new cities (case study basmaya city - republic of Iraq) An analytical study of strength, weakness, opportunity, and threat. IOP Conference Series: Earth and Environmental Science, 459: $\quad 062108$. https://doi.org/10.1088/1755$1315 / 459 / 6 / 062108$

[49] Faris, H.M., Griffin, K.A. (2020). The impact of COVID19 on religious tourism and pilgrimage to the holy city of Karbala. International Journal of Religious Tourism and Pilgrimage, 8(7).

[50] Alwan, N.A. (2007). Holy city of Karbala and the possibility of advancement the level of religious tourism (case study). Journal of Administration and Economics, (66).

[51] International Center for Technical Research. (2007). Kerbala Master plan Update. In Iraqi Ministry of Municipalities and Public Works (Ed.), Setting and Evaluating of Alternatives Stages Report. 